\title{
Association Between Perceived Health Care Stigmatization and BMI Change
}

\author{
Lena M. Hansson Finn Rasmussen \\ Department of Public Health Sciences, Karolinska Institutet, Stockholm, Sweden
}

\section{Key Words}

Obesity $\cdot$ Prejudice $\cdot$ Primary health care $\cdot$ Gender identity $\cdot$ Body weight changes

\begin{abstract}
Background/Aims: This study examined the association between experiences of health care stigmatization and BMI changes in men and women with normal weight and obesity in Sweden. Methods: The participants were drawn from a population-based survey in Sweden (1996-2006), and data on their perceived health care stigmatization were measured in 2008. They were categorized in individuals with normal weight $(n=1,064)$, moderate obesity $(n=$ $1,273)$, and severe obesity $(n=291)$. The main outcome measure was change in BMI. Results: Individuals with severe obesity experiencing any health care stigmatization showed a BMI increase by $1.5 \mathrm{~kg} / \mathrm{m}^{2}$ more than individuals with severe obesity with no such experience. For individuals with moderate obesity, insulting treatment by a physician and avoidance of health care were associated with a relative BMI increase of 0.40 and $0.75 \mathrm{~kg} / \mathrm{m}^{2}$, respectively, compared with their counterparts who did not experience stigmatization in these areas. No difference in experience of any form of health care stigmatizing associated BMI change was observed for men and women with normal weight. Conclusion: In this large, population-based study, perceived health care stigmatization was associated with an increased relative BMI in individuals with severe obesity. For moderate obesity, the evidence of an association was inconclusive.

(c) 2014 S. Karger GmbH, Freiburg
\end{abstract}

\section{Introduction}

Stigmatization of people with obesity has been well-documented in different settings, but has been shown to be prevalent even in health and medical care [1]. Despite this, there are several important gaps in the field of obesity stigmatization, such as knowledge of possible consequences of health care stigmatization [1]. According to Link and Phelan [2], stigma or 
Hansson and Rasmussen: Association Between Perceived Health Care Stigmatization and BMI Change

stigmatization should be seen as a broad concept that includes different processes, such as the labelling and stereotyping of the stigmatized group, separation as well as status loss and discrimination, acting together in a power situation. The power relations between health care professionals and patients therefore have the potential to promote stigmatization. However, primary health care professionals are trained to support their patients in adopting healthy lifestyles and may therefore be less stigmatizing. Nevertheless, research shows that a range of negative beliefs and stereotypes about obesity exist among health care professionals, as well as a feeling of ambivalence towards patients with obesity [3]. In quantitative studies, for example, general practitioners and nurses in primary care regard lack of motivation and noncompliance among their patients as the main problems when treating obesity $[4,5]$. These attitudes and feelings could directly or indirectly affect the encounters between patients with obesity and health care professionals. On the other hand, qualitative research argues that views on patients with obesity are more balanced, and, despite frustration about adherence, health care professionals express an interest in establishing a good patient-provider relationship [6,7]. Nor are reports of patients' experiences of provider treatment always negative $[8,9]$. It may be that patients with obesity to some extent lost their ability to accurately perceive the attitudes of others during personal interactions, due to past experiences that have made them insensitive to disrespectful behaviors [10,11].

However, stigmatization may undermine the possibility of people with obesity to receive adequate care. For example, there are indications that physicians spend less time with overweight than normal-weight individuals [12], and provide less health education to the former [13]. This is alarming, since this group needs adequate information and resources for improving lifestyle. Stigmatization may also affect people's help-seeking behaviors. Studies show that people with obesity are less likely to take part in health-promoting services and screening for early disease detection, and may delay medical care due to disrespectful treatment $[1,3]$. The authors of the present study previously reported that people with obesity regarded the health care setting as the most intimidating when given the options of different settings [14]. Furthermore, women with a BMI of $35 \mathrm{~kg} / \mathrm{m}^{2}$ or more were found to be about three times more likely than men with the same BMI to have experienced negative encounters in health care. Similar results were documented in a population-based study from the USA [15]. Given that the cultural value of thinness is imposed on women in particular [16], they may be more vulnerable than men. However, more research is needed to ascertain whether gender is a relevant aspect of obesity stigmatization in health care.

Thus, a range of studies confirms negative encounters in health care. Less is known, however, about the consequences of these experiences, such as physical ill-health or psychological distress. Stigma has the potential to produce stress responses in the individual [17], and stress is a known risk factor for hypertension, diabetes, depression, and weight gain [18]. Research suggests that obesity stigmatization in general may not only contribute to psychological distress (e.g., depression, low self-esteem and body dissatisfaction), but also to unhealthy behaviors (e.g., binge eating, eating restraint, overeating and avoidance of physical activity) $[1,19]$. Consequently, stigmatization may result in behaviors that counteract weight loss. To give an example, research on a small clinical sample of mainly overweight women reported that interpersonal stigmatization, such as inappropriate comments from doctors, predicted poorer weight loss treatment outcomes [20].

Unfortunately, most studies within the obesity field have been cross-sectional so that there is only weak evidence for stigmatization leading to negative physical consequences. However, longitudinal studies in the field of ethnic discrimination indicate that stigmatization may increase the risk of weight gain [21] and accumulating visceral fat [22]. Interpersonal discrimination has been shown to increase both men's and women's waist circumference over a 9-year period [23]. Stigmatization in the delivery of health care and subse- 
Hansson and Rasmussen: Association Between Perceived Health Care Stigmatization and BMI Change

quent weight change, to our knowledge, has scarcely been investigated. In the present study, we investigated body mass changes in a large population-based sample, which included men and women with both normal weight and obesity. Furthermore, this study was based on natural body mass change, since the participating individuals were not recruited from weight loss treatment programs. We hypothesize that there is an association between experiences of stigmatization in health care and an increase in BMI among people with obesity, and that the strength of this association turns out stronger for individuals with higher BMI.

\section{Material and Methods}

\section{Study Population}

The Swedish Survey of Living Conditions (ULF) has been carried out annually since 1975 by Statistics Sweden. This survey uses a random representative sample of the Swedish population aged 16-84 years to investigate, inter alia, people's general health, lifestyles, and participation in the society. The ULF also provides information on height and weight between 1996 and 2006. We conducted a follow-up study, where we invited 5,018 men and women, aged 25-64 years in 2008, with normal weight (BMI $18.5-24.9 \mathrm{~kg} / \mathrm{m}^{2}$ ), moderate obesity (BMI $30.0-34.9 \mathrm{~kg} / \mathrm{m}^{2}$ ), and severe obesity (BMI $\geq 35 \mathrm{~kg} / \mathrm{m}^{2}$ ) at the time of their participation in the ULF survey. Further details on the sample and methodology were given in a previous publication, which investigated the association between weight status and perceived discrimination in different domains of life, including health care [14]. The Regional Ethical Review Board of the Karolinska Institutet (Stockholm, Sweden) approved this study.

\section{Perceived Health Care Stigmatization}

The measure of health care stigmatization was based on one question ('Have you ever been unfairly denied or provided with inferior medical care?'), which had been used previously in the USA for research on weight discrimination [24]. Three additional questions were asked to capture interpersonal stigmatizing experiences in health care ('Have you ever felt insulted by something a physician has said at a primary health care visit?'. 'Have you ever felt insulted by something a nurse has said at a primary health care visit?'), and avoidance of contact with health care services due to stigmatization ('Have you ever avoided seeking health care due to fear of being subjected to insulting treatment?'). Health care stigmatization was defined as ever having experienced any of these four situations. The different situations were also investigated separately. In a pilot study with individuals with obesity and normal weight $(n=29)$, we investigated the 3-week testretest reliability of the question of having been provided inferior medical care. The simple Kappa for agreement was 0.75 , which indicated satisfactory reliability for that item.

\section{Independent Variables and Confounders}

\section{Register Data}

Some of the sociodemographic data on study participants was collected from the Population and Housing Censuses (PHC) and the Longitudinal Database of Education, Income and Occupation (LISA) held by Statistics Sweden. The education level was categorized as low, medium high, or high. Data on marital status was categorized as married, unmarried, or other (widowed/divorced). The place of residence was categorized into urban, semi-urban, or rural areas. The current disposable income was obtained from LISA. The national background was categorized into Swedish or foreign. More details on the variables used can be found elsewhere [14].

\section{$U L F$}

We recruited people in all years between 1996 and 2006 to build up as large a sample as possible. This means that the baseline data on participants' height and weight were assessed at different points in time. Height and weight were self-reported. BMI was calculated as weight $(\mathrm{kg})$ divided by height squared $\left(\mathrm{m}^{2}\right)$, and 
Hansson and Rasmussen: Association Between Perceived Health Care Stigmatization and BMI Change

categorized as normal weight (BMI $18.5-24.9 \mathrm{~kg} / \mathrm{m}^{2}$ ), moderate obesity (BMI 30.0-34.9 kg/m²), and severe obesity (BMI $\geq 35 \mathrm{~kg} / \mathrm{m}^{2}$ ). Individuals also self-reported on their various long-term physical and psychological problems.

\section{Follow-Up Survey (2008)}

The participants reported their height and weight themselves, and pregnant women were asked to report their weight before pregnancy. The self-reported employment was categorized as employed or student; self-employed; sick-leave for at least 3 months or disability pension; unemployed or other. A short version of the Marlowe-Crowne Social Desirability Scale [25] was used to measure social desirability. The global self-esteem was measured on Rosenberg's Self-Esteem Scale [26]. Additional details on internal consistencies of the scales in this sample can be found in the previous publication [14].

\section{Statistical Analyses}

We performed multiple linear regression analyses in STATA (StataCorp LP, College Station, TX, USA) with robust variance correction to estimate whether perceived health care stigmatization was associated with BMI change. Possible interactions between health care stigmatization, weight status, and gender in relation to BMI change were also investigated. The model can be written: $\mathrm{BMI}_{\text {change }}=\beta_{0}+\beta_{\text {health care stigmatization }}$ $($ no $=0$, yes $=1)+\beta_{\text {normal weight }=0 \text {, moderate obesity }=1}+\beta_{\text {normal weight }=0 \text {, severe obesity }=1}+\beta_{\text {health care stigmatization }(\text { no }=0, \text { yes }=1)} \times$ normal weight $=0$, moderate obesity $=1+\beta_{\text {health care stigmatization (no }=0 \text {, yes }=1)} \times$ normal weight $=0$, severe obesity $=1+\beta_{\text {confounding variables }}$ $(1-14)+b_{i}$ (random effects).

Thus, the BMI changes for individuals with normal weight not having experienced stigmatization are

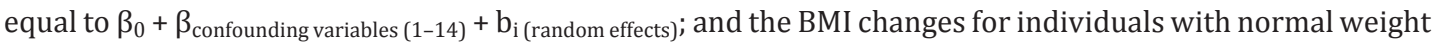
having experienced stigmatization equal $\beta_{0}+\beta_{\text {health care stigmatization (no }=0 \text {, yes }=1)}+\beta_{\text {confounding variables (1-14) }}+b_{i}$ (random effects). BMI changes in individuals with moderate obesity with and without experiences of health care stigmatization are $\beta_{0}+\beta_{\text {normal weight }=0 \text {, moderate obesity }=1}+\beta_{\text {confounding variables (1-14) }}+b_{i \text { (random effects) }}$ and $\beta_{0}+\beta_{\text {health }}$

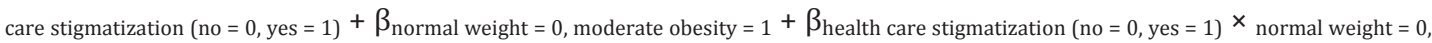

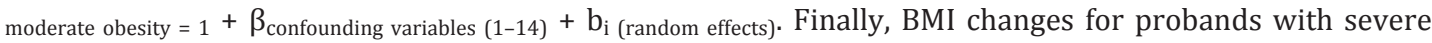
obesity conform to $\beta_{0}+\beta_{\text {normal weight }=0 \text {, severe obesity =1 }}+\beta_{\text {confounding variables (1-14) }}+b_{i \text { (random effects) }}$ and $\beta_{0}+\beta_{\text {health }}$ care stigmatization (no =0, yes =1) $+\beta_{\text {normal weight }=0 \text {, severe obesity }=1}+\beta_{\text {health care stigmatization }(\text { no }=0 \text {, yes }=1)} \times$ normal weight $=0$, severe obesity $=1+\beta_{\text {confounding variables (1-14) }}+b_{\text {i (random effects) }}$.

Height and weight were reported at time of participation in the ULF (1996-2006, T1) and in 2008 (T2). Perceived health care stigmatization was reported retrospectively in 2008. First, we controlled for variables potentially related to weight, such as age, sex, place of residence, national background, marital status, and comorbidities. Because the space of time between the baseline and the follow-up assessments of height and weight varied between the participants, a time adjustment was made. We also adjusted for current marital status, current income, attained education, and employment status - all of which might have influenced the reporting of perceived stigmatization. Finally, individuals' self-esteem and social desirability were included, since both factors have been proven to be associated with perceived stigmatization [27].

\section{Results}

\section{Sample Characteristics}

Of the 5,018 individuals who were asked to participate, 2,788 responded (56\%). The analytical sample included 1,064 individuals with normal weight, 1,273 individuals with moderate obesity, and 291 individuals with severe obesity. Data on response rates within different subgroups, missing data, and descriptive statistics by BMI status have been reported elsewhere [14].

The prevalence of ever having experienced health care stigmatization was 34\% in women and 16\% in men. The prevalence in the different BMI categories was as follows: men with normal weight $12 \%$, men with moderate obesity $17 \%$, men with severe obesity $24 \%$, 
Hansson and Rasmussen: Association Between Perceived Health Care Stigmatization and BMI Change

Table 1. Crude BMI change (mean \pm SD) between T1 and T2 in the different BMI status groups according to sex and perceived health care stigmatization

\begin{tabular}{|c|c|c|c|c|c|c|}
\hline & \multicolumn{3}{|c|}{ No perceived health care stigmatization } & \multicolumn{3}{|c|}{ Perceived health care stigmatization } \\
\hline & $\mathrm{T} 1$ & $\mathrm{~T} 2$ & $\mathrm{~T} 2-\mathrm{T} 1$ & $\mathrm{~T} 1$ & $\mathrm{~T} 2$ & T2-T1 \\
\hline \multicolumn{7}{|l|}{ Men } \\
\hline Normal weight & $22.8 \pm 0.1$ & $23.9 \pm 0.1$ & $1.1 \pm 0.1$ & $22.8 \pm 0.2$ & $23.8 \pm 0.3$ & $1.0 \pm 0.3$ \\
\hline Moderate obesity & $31.5 \pm 0.1$ & $31.8 \pm 0.1$ & $0.4 \pm 0.1$ & $32.1 \pm 0.1$ & $32.7 \pm 0.3$ & $0.6 \pm 0.3$ \\
\hline $\begin{array}{l}\text { Severe obesity } \\
\text { Women }\end{array}$ & $37.2 \pm 0.2$ & $36.7 \pm 0.5$ & $-0.5 \pm 0.4$ & $38.0 \pm 0.5$ & $38.7 \pm 1.0$ & $0.7 \pm 0.9$ \\
\hline Normal weight & $22.1 \pm 0.1$ & $22.9 \pm 0.1$ & $0.8 \pm 0.1$ & $22.0 \pm 0.1$ & $23.0 \pm 0.2$ & $1.0 \pm 0.2$ \\
\hline Moderate obesity & $31.6 \pm 0.1$ & $32.2 \pm 0.2$ & $0.6 \pm 0.2$ & $32.0 \pm 0.1$ & $33.2 \pm 0.3$ & $1.2 \pm 0.3$ \\
\hline Severe obesity & $37.8 \pm 0.3$ & $37.1 \pm 0.7$ & $-0.7 \pm 0.7$ & $38.9 \pm 0.4$ & $40.0 \pm 0.6$ & $1.1 \pm 0.6$ \\
\hline
\end{tabular}

$\mathrm{T} 1=1996-2006 ; \mathrm{T} 2=2008$.

women with normal weight $28 \%$, women with moderate obesity $34 \%$, and women with severe obesity $52 \%$. Thus, there was a twofold difference in having experienced health care stigmatization between men and women, regardless of BMI category status $\left(\chi^{2}(1)=110 ; p\right.$ $<0.001)$.

\section{Health Care Stigmatization and BMI Change}

The unadjusted BMI changes among each BMI status group in relation to perceived stigmatization is given in table 1. All groups increased their BMI over the study period, except women and men with severe obesity not having experienced health care stigmatization, and men with severe obesity having experienced health care stigmatization. Men and women with obesity who had experienced health care stigmatization had a higher initial BMI than their pendants who had not experienced stigmatization.

After adjusting for all the confounding variables, mentioned and proposed in 'Statistical Analyses' (excluding the interaction terms 'health care stigmatization' and 'BMI status group'), we found a significant independent association between perceived health care stigmatization and BMI change for the whole studied population $(\beta=0.31$; confidence interval $=0.01,0.62)$. In terms of possible effect modifications, no significant interaction was found between gender and health care stigmatization $(\beta=0.35$; confidence interval $=-0.25,0.94)$.

However, there was a significant interaction between BMI category and perceived health care stigmatization after adjusting for confounders and gender (table 2). Individuals with severe obesity who had experienced stigmatization exhibited a relative BMI change difference of $1.46 \mathrm{~kg} / \mathrm{m}^{2}$ compared with those with severe obesity who had not experienced stigmatization. For moderate obesity, there was a relative BMI change difference of $0.32 \mathrm{~kg} / \mathrm{m}^{2}$, and for normal weight the difference was $0.11 \mathrm{~kg} / \mathrm{m}^{2}$. However, the latter was in the opposite direction, meaning that normal-weight individuals who had experienced stigmatization had lost more weight than normal-weight individuals who had not (not significant).

When comparing individuals with normal weight that experienced stigmatization with individuals with moderate and severe obesity having experienced stigmatization, the relative BMI changes were 0.22 and $0.34 \mathrm{~kg} / \mathrm{m}^{2}$, respectively. Consequently, the relative BMI change difference between individuals with moderate and severe obesity having experienced stigmatization was $0.12 \mathrm{~kg} / \mathrm{m}^{2}$; however, this was not statistically significant. 
Hansson and Rasmussen: Association Between Perceived Health Care Stigmatization and BMI Change

Table 2. Associations between perceived health care stigmatization (overall, received inferior medical care, insulting treatment by doctor or nurse, avoidance of health care due to fear of insulting treatment) and BMI change in $\mathrm{kg} / \mathrm{m}^{2}$, adjusted for confounding variables ${ }^{\mathrm{a}}$; the $\beta$-coefficient (B) with 95\% confidence interval (CI) describes the BMI change

\begin{tabular}{|c|c|c|c|c|c|c|c|c|c|c|}
\hline & \multicolumn{2}{|c|}{ Overall } & \multicolumn{2}{|c|}{$\begin{array}{l}\text { Inferior medical } \\
\text { care }\end{array}$} & \multicolumn{2}{|c|}{$\begin{array}{l}\text { Insulting } \\
\text { treatment by } \\
\text { nurse }\end{array}$} & \multicolumn{2}{|c|}{$\begin{array}{l}\text { Insulting } \\
\text { treatment by } \\
\text { physician }\end{array}$} & \multicolumn{2}{|c|}{$\begin{array}{l}\text { Avoidance of } \\
\text { health care }\end{array}$} \\
\hline & $\mathrm{B}$ & $\mathrm{CI}$ & B & CI & B & CI & B & CI & $\mathrm{B}$ & CI \\
\hline HCS $($ no $=0$, yes $=1)$ & -0.11 & $\begin{array}{l}-0.44 \\
0.23\end{array}$ & -0.50 & $\begin{array}{l}-1.13 \\
0.14\end{array}$ & -0.02 & $\begin{array}{l}-0.52 \\
0.49\end{array}$ & -0.28 & $\begin{array}{l}-0.64 \\
0.08\end{array}$ & -0.62 & $\begin{array}{l}-1.13 \text {; } \\
-0.11\end{array}$ \\
\hline \multicolumn{11}{|l|}{ Body weight ${ }^{b}$} \\
\hline Moderate obesity & -0.21 & $\begin{array}{l}-0.97 \\
0.55\end{array}$ & -0.29 & $\begin{array}{l}-1.06 \\
0.48\end{array}$ & -0.29 & $\begin{array}{l}-1.06 \\
0.48\end{array}$ & -0.24 & $\begin{array}{l}-0.99 \\
0.52\end{array}$ & -0.32 & $\begin{array}{l}-1.09 \\
0.44\end{array}$ \\
\hline \multirow{2}{*}{$\begin{array}{l}\text { Severe obesity } \\
\text { HCS } \times \text { body weight }\end{array}$} & -1.23 & $\begin{array}{l}-2.60 \\
0.15\end{array}$ & -1.14 & $\begin{array}{l}-2.49 \\
0.20\end{array}$ & -1.09 & $\begin{array}{l}-2.44 \\
0.26\end{array}$ & -1.09 & $\begin{array}{l}-2.48 \\
0.29\end{array}$ & -1.06 & $\begin{array}{l}-2.43 \text {; } \\
0.31\end{array}$ \\
\hline & & & & & & & & & & \\
\hline \multirow{3}{*}{$\begin{array}{l}\text { HCS }(\text { no }=0, \text { yes }=1) \times \\
\text { moderate obesity } \\
\text { HCS }(\text { no }=0, \text { yes }=1) \times \\
\text { severe obesity }\end{array}$} & 0.43 & $\begin{array}{l}-0.12 ; \\
0.97\end{array}$ & -0.19 & $\begin{array}{l}-1.17 \\
0.80\end{array}$ & 0.28 & $\begin{array}{l}-0.57 \\
1.14\end{array}$ & 0.68 & $\begin{array}{l}0.10 \\
1.26\end{array}$ & 1.49 & $\begin{array}{l}0.57 \\
2.42\end{array}$ \\
\hline & 1.57 & $\begin{array}{l}0.41 \\
2.74\end{array}$ & 1.23 & $\begin{array}{l}-0.69 \\
3.15\end{array}$ & 1.22 & $\begin{array}{l}-0.45 \\
2.90\end{array}$ & 1.52 & $\begin{array}{l}0.33 \\
2.71\end{array}$ & 1.96 & $\begin{array}{l}0.26 \\
3.65\end{array}$ \\
\hline & \multicolumn{2}{|c|}{$\begin{array}{l}\mathrm{F}(25,2,602)= \\
6.32, \mathrm{p}<0.001 \\
\mathrm{R}^{2}=0.055\end{array}$} & \multicolumn{2}{|c|}{$\begin{array}{l}\mathrm{F}(25,2,581)= \\
5.82, \mathrm{p}<0.001 \\
\mathrm{R}^{2}=0.052\end{array}$} & \multicolumn{2}{|c|}{$\begin{array}{l}F(25,2,590)= \\
5.58, p<0.001 \\
\mathrm{R}^{2}=0.051\end{array}$} & \multicolumn{2}{|c|}{$\begin{array}{l}\mathrm{F}(25,2,592)= \\
5.94, \mathrm{p}<0.001 \\
\mathrm{R}^{2}=0.054\end{array}$} & \multicolumn{2}{|c|}{$\begin{array}{l}\mathrm{F}(25,2,585)= \\
6.07, \mathrm{p}<0.001, \\
\mathrm{R}^{2}=0.055\end{array}$} \\
\hline
\end{tabular}

${ }^{\mathrm{a}}$ Gender, BMI at T1, time between BMI measurements, age, marital status at T1 and T2, place of residence at T1, attained education at T2, national background, income at T2, employment status at T2, co-morbidity at T1, self-esteem at T2 and social desirability at T2.

${ }^{\mathrm{b}}$ Normal weight $=$ reference.

HCS = Health care stigmatization; T1 = 1996-2006; T2 = 2008 .

In table 2, the associations between different types of health care stigmatization and BMI change are also reported. The pattern of association was almost the same for the respective stigmatization types as for the overall measure, except for 'receiving inferior medical care' and 'insulting treatment by nurse', where there was no statistically significant interaction between BMI category and perceived health care stigmatization.

\section{Discussion}

\section{Summary of Main Findings}

The present study shows that stigmatization in health care is associated with body mass development of individuals with severe obesity. We found a relative BMI change difference of $1.46 \mathrm{~kg} / \mathrm{m}^{2}$ between individuals with severe obesity subjected to stigmatization and individuals with severe obesity not having experienced stigmatization over the study period. This corresponds to a 4-kg weight increase for a woman $165 \mathrm{~cm}$ in height and weighing $100 \mathrm{~kg}$. There were, however, no significant differences in relative BMI change between individuals with severe obesity having experienced stigmatization in health care and individuals with normal weight or moderate obesity having experienced stigmatization. However, we found it more relevant to compare BMI changes within the BMI status groups, since we considered it more likely that stigmatization in health care would occur among people with obesity, due to their weight, than among people with normal weight. 
Hansson and Rasmussen: Association Between Perceived Health Care Stigmatization and BMI Change

Puhl and Brownell [28] suggested that obesity stigmatization in health care may result in worse self-care and potentially unhealthier behaviors, which may lead to poorer outcomes in weight loss. In terms of the BMI change difference, the individuals with severe obesity not having experienced health care stigmatization had actually lost body mass at follow-up; this may indicate that positive encounters in health care supported them in losing weight, while their counterparts with experiences of health care stigmatization increased their weight. This interpretation would support Puhl and Brownell's theory.

The clinical significance of a relative BMI difference of $1.46 \mathrm{~kg} / \mathrm{m}^{2}$ for people with severe obesity is difficult to estimate. However, not only stigmatization per se can contribute to psychosocial stress and low self-esteem; people's perception of failure in losing weight may produce the same. For people with severe obesity, any risk factor for weight gain should be prevented, especially since it has been suggested that among this group modest weight losses of $5 \%$ can cause significant health benefits [29].

Our results show that interpersonal stigmatization has a strong connection with weight gain. That is, there was a significant relative BMI change difference between individuals with both moderate and severe obesity, who had experienced insulting treatment by a physician and avoided health care due to fear of being subjected to insulting treatment, and individuals who had not had such an experience. In contrast, having been provided inferior medical care, possibly originating from both institutional (examination equipment does not fit people with obesity) as well as interpersonal stigmatization, did not show an association with weight change. Thus, health care personnel seem to have an important role to play in creating supportive and positive encounters with people with obesity.

\section{Comparison with Existing Literature}

As mentioned in the 'Introduction', we are not aware of any study that investigated health care stigmatization and BMI change in a population-based sample. Previous studies of interest mainly examined small clinical samples with predominantly female overweight participants $[20,30]$. A further limitation of these studies has been that the outcome measure was not always exclusively concerned with health care stigmatization. However, one of the studies found a weak association between weight loss and interpersonal stigmatization (e.g., inappropriate comments by doctors, children or family) [20]. More grave stigmatizing experiences were associated with a greater total caloric intake and fewer calories expended through physical activity [20]. The other study of interest found that nasty comments from doctors were associated with exercise avoidance [30]. Components that can influence weight change seem to have a relation with stigmatization.

The present study showed that interpersonal stigmatizing experiences had a significant impact on the weight development of individuals with obesity. This is consistent with previous research showing that interpersonal stigmatization has a stronger relationship with poorer weight loss outcomes than institutional stigmatization [20,30]. It may be that hurtful and insulting comments expressed in an interpersonal encounter result in psychological distress to a higher degree, mainly because the very people that one would expect to be supportive fail to be so. On the other hand, it has also been suggested in the literature published thus far that stigmatization may act as a motivator for change. The desire to avoid weight-related stress (obesity stigmatization) may accordingly reinforce people's efforts to lose and maintain weight [31]. However, our results point in the direction of potential harmful effects of health care stigmatization. 
Hansson and Rasmussen: Association Between Perceived Health Care Stigmatization and BMI Change

\section{Strengths and Limitations of the Study}

The strength of the present study lies in its nationwide coverage and the inclusion of male participants. To the best of our knowledge, this is the first study to investigate the physical consequences of health care stigmatization, with a strong focus on obesity as a possible cause of mistreatment. Additionally, few studies included a comparison group (normal weight versus obesity). Regarding limitations, the self-reporting of height and weight certainly poses a threat to the validity of our results. People with obesity often underreport their weight [32]. This would lead to an underestimation of the relative BMI change difference, especially between individuals with normal weight and those with severe obesity. In other words, the BMI change difference would have been larger if the weight had been objectively measured. Even though we do not know if people who have been stigmatized tend to underreport their weight to a greater degree than people who have not, we have no reason to believe that the outcomes (relative BMI change difference) within the BMI groups would not be valid. A higher BMI at T1 was noted for individuals with obesity who had experienced stigmatization than for those who had not. This is what might be expected because a higher BMI is related to a higher risk of being stigmatized [14]. BMI at T1 was adjusted for in the analysis, but matching the groups according to BMI would have been a better approach. The retrospective reporting of stigmatizing experiences, and the lack of information on point in time, duration, and frequency of the stigmatizing incidents, did not allow claims of causality. Furthermore, the time period between baseline and follow-up differed for the included individuals, which of course could introduce bias in the estimates.

Consideration of health care providers' behaviors' contribution to disparities in medical care for people with obesity is just in its infancy. Few studies have been specifically designed to test the effect of stigmatizing encounters in health care, and many measures relevant for this task originate in the research field of racial discrimination (which were also used in the present study). Even though research dealing with racial discrimination has a longer history than investigations on obesity discrimination, it is also subjected to many methodological pitfalls, such as the absence of theoretical frameworks, weak psychometric properties of the measures used, and the vagueness of the time frames used for asking about experiences of stigmatization [33]. Earlier research within the field of racism indicates that everyday discrimination, or chronic exposure to stigmatization, is a better predictor of health status than major negative life-changing experiences [34]. These shortcomings are also present in the current work. For example, the single-item global measure 'ever experiencing inferior medical care' may be too vague to apply to people with obesity. Furthermore, avoidance of health care due to fear of insulting treatment could be regarded as a consequence of experienced stigmatization rather than as an actual stigmatizing situation. But it may also be seen as a form of selfstigmatization. New methods for and approaches to measuring obesity stigmatization in health care are urgently needed.

Several factors may be associated with people's weight increase. These factors may also differ between people with normal weight and those with obesity. Among people with severe obesity, greater genetic susceptibility to weight gain could be one reason [35]. However, it is doubtful that this would only co-exist with individuals with severe obesity experiencing stigmatization, and not among those not experiencing stigmatization. It is more likely that people experiencing stigmatization due to their obesity are those who cannot blame their weight gain on genetics $[6,36]$. An additional limitation was that we had no information on behavioral measures, such as dieting, participation in weight loss programs, obesity surgery, or dietary intake and physical activity between the two BMI measurements. These behaviors and practices can of course influence weight change to a great degree, and some of them are evidently more common among people with severe obesity. 
Hansson and Rasmussen: Association Between Perceived Health Care Stigmatization and BMI Change

\section{Implications for Future Research and Clinical Practice}

Although much research has documented the high prevalence of stigmatization of individuals with obesity in health care, there is still limited evidence regarding the possible consequences. Future research has to combine longitudinal designs with valid measures of stigmatization and BMI.

In a recent study, it was proposed that general stigmatization aggravated the effects of biological risk factors, such as abdominal obesity, on the risk of developing diabetes [37]. Additionally, a randomized control treatment study found that teaching acceptance-based strategies to cope with obesity-related stigmatization among patients with obesity resulted in greater improvements in body mass, quality of life, and psychological distress at 3-month follow-up, compared with control patients placed on a waiting list, who were offered the intervention after follow-up [38].

There seems to be an urgent need for health care professionals to not only apply strategies that promote healthy behaviors with regard to physical activity and diet, but also to adopt a respectful attitude when encountering patients with severe obesity. Helping people to find effective coping skills may also be an important task.

\section{Acknowledgement}

We thank Statistics Sweden for the critical revision of the questionnaire, sampling procedure, and data collection. Parts of this work were presented at the 11th International Congress of Behavioral Medicine, August 4-7, 2010, Washington, DC, USA. This research received no specific grant from any funding agency in the public, commercial, or not-for-profit sector.

\section{Disclosure Statement}

We have no conflict of interest to declare.

\section{References}

Puhl RM, Heuer CA: The stigma of obesity: a review and update. Obesity (Silver Spring) 2009;17:941-964. Link BG, Phelan JC: Conceptualizing stigma. Ann Rev Sociol 2001;27:363-385.

3 Mold F, Forbes A: Patients' and professionals' experiences and perspectives of obesity in health-care settings: a synthesis of current research. Health Expect 2013;16:119-142.

4 Bocquier A, Verger P, Basdevant A, Andreotti G, Baretge J, Villani P, Paraponaris A: Overweight and obesity: knowledge, attitudes, and practices of general practitioners in France. Obes Res 2005;13:787-795.

5 Brown I, Stride C, Psarou A, Brewins L, Thompson J: Management of obesity in primary care: nurses' practices, beliefs and attitudes. J Adv Nurs 2007;59:329-341.

6 Brown I, Thompson J: Primary care nurses' attitudes, beliefs and own body size in relation to obesity management. J Adv Nurs 2007;60:535-543.

7 Hansson LM, Rasmussen F, Ahlström GI: General practitioners' and district nurses' conceptions of the encounter with obese patients in primary health care. BMC Fam Pract 2011;12:7.

$\rightarrow 8$ Wadden TA, Anderson DA, Foster GD, Bennett A, Steinberg C, Sarwer DB: Obese women's perceptions of their physicians' weight management attitudes and practices. Arch Fam Med 2000;9:854-860.

-9 Fong RL, Bertakis KD, Franks P: Association between obesity and patient satisfaction. Obesity (Silver Spring) 2006;14:1402-1411.

10 Beach MC, Roter DL, Wang NY, Duggan PS, Cooper LA: Are physicians' attitudes of respect accurately perceived by patients and associated with more positive communication behaviors? Patient Educ Couns 2006;62:347354.

11 Gudzune KA, Huizinga MM, Beach MC, Cooper LA: Obese patients overestimate physicians' attitudes of respect. Patient Educ Couns 2012;88:23-28. 
Hansson and Rasmussen: Association Between Perceived Health Care Stigmatization and BMI Change

12 Hebl MR, Xu J, Mason MF: Weighing the care: Patients' perceptions of physician care as a function of gender and weight. Int J Obes Relat Metab Disord 2003;27:269-275.

13 Bertakis KD, Azari R: The impact of obesity on primary care visits. Obes Res 2005;13:1615-1623.

14 Hansson LM, Näslund E, Rasmussen F: Perceived discrimination among men and women with normal weight and obesity. A population-based study from Sweden. Scand J Public Health 2010;38:587-596.

15 Andreyeva T, Puhl RM, Brownell KD: Changes in perceived weight discrimination among Americans, 19951996 through 2004-2006. Obesity (Silver Spring) 2008;16:1129-1134.

16 McLaren L, Godley J: Social class and BMI among Canadian adults: a focus on occupational prestige. Obesity (Silver Spring) 2009;17:290-299.

17 Guyll M, Matthews KA, Bromberger JT: Discrimination and unfair treatment: relationship to cardiovascular reactivity among African American and European American women. Health Psychol 2001;20:315-325.

18 McEwen BS: Central effects of stress hormones in health and disease: Understanding the protective and damaging effects of stress and stress mediators. Eur J Pharmacol 2008;583:174-185.

19 Puhl RM, Heuer CA: Obesity stigma: important considerations for public health. Am J Public Health 2010;100: 1019-1028.

-20 Wott CB, Carels RA: Overt weight stigma, psychological distress and weight loss treatment outcomes. J Health Psychol 2010;15:608-614.

21 Cozier YC, Wise LA, Palmer JR, Rosenberg L: Perceived racism in relation to weight change in the Black Women's Health Study. Ann Epidemiol 2009;19:379-387.

22 Lewis TT, Kravitz HM, Janssen I, Powell LH: Self-reported experiences of discrimination and visceral fat in middle-aged African-American and Caucasian women. Am J Epidemiol 2011;173:1223-1231.

23 Hunte HE: Association between perceived interpersonal everyday discrimination and waist circumference over a 9-year period in the Midlife Development in the United States cohort study. Am J Epidemiol 2011;173: 1232-1239.

24 Carr D, Friedman MA: Is obesity stigmatizing? Body weight, perceived discrimination, and psychological wellbeing in the United States. J Health Soc Behav 2005;46:244-259.

-25 Rudmin FW: Norwegian short-form of the Marlowe-Crowne Social Desirability Scale. Scand J Psychol 1999; 40:229-233.

26 Rosenberg M: Society and the Adolescent Self-Image. Middletown, Wesleyan University Press, 1989.

-27 Gee GC, Ro A, Gavin A, Takeuchi DT: Disentangling the effects of racial and weight discrimination on body mass index and obesity among Asian Americans. Am J Public Health 2008;98:493-500.

28 Puhl R, Brownell KD: Bias, discrimination, and obesity. Obes Res 2001;9:788-805.

29 Wing RR, Lang W, Wadden TA, Safford M, Knowler WC, Bertoni AG, Hill JO, Brancati FL, Peters A, Wagenknecht L; Look AHEAD Research Group: Benefits of modest weight loss in improving cardiovascular risk factors in overweight and obese individuals with type 2 diabetes. Diabetes Care 2011;34:1481-1486.

-30 Vartanian LR, Shaprow JG: Effects of weight stigma on exercise motivation and behavior: a preliminary investigation among college-aged females. J Health Psychol 2008;13:131-138.

-31 Latner JD, Wilson GT, Jackson ML, Stunkard AJ: Greater history of weight-related stigmatizing experience is associated with greater weight loss in obesity treatment. J Health Psychol 2009;14:190-199.

-32 Shields M, Gorber SC, Tremblay MS: Effects of measurement on obesity and morbidity. Health Rep 2008;19: 77-84.

-33 Kressin NR, Raymond KL, Manze M: Perceptions of race/ethnicity-based discrimination: a review of measures and evaluation of their usefulness for the health care setting. J Health Care Poor Underserved 2008;19:697730.

-34 Williams DR, Yu Y, Jackson JS, Anderson NB: Racial differences in physical and mental health: socio-economic status, stress and discrimination. J Health Psychol 1997;2:335-351.

35 den Hoed M, Ekelund U, Brage S, Grontved A, Zhao JH, Sharp SJ, Ong KK, Wareham NJ, Loos RJ: Genetic susceptibility to obesity and related traits in childhood and adolescence: influence of loci identified by genome-wide association studies. Diabetes 2010;59:2980-2988.

-36 O'Brien KS, Puhl RM, Latner JD, Mir AS, Hunter JA: Reducing anti-fat prejudice in preservice health students: a randomized trial. Obesity (Silver Spring) 2010;18:2138-2144.

37 Tsenkova VK, Carr D, Schoeller DA, Ryff CD: Perceived weight discrimination amplifies the link between central adiposity and nondiabetic glycemic control (HbA1c). Ann Behav Med 2011;41:243-251.

38 Lillis J, Hayes SC, Bunting K, Masuda A: Teaching acceptance and mindfulness to improve the lives of the obese: a preliminary test of a theoretical model. Ann Behav Med 2009;37:58-69. 